Vol. 11 (1): 19-26 (2021)

\title{
TRANSFORMATION OF GEOSYSTEMS VEGETATION OF SOUTHERN PRE - BAIKAL (The Baikal Region)
}

\author{
Tatyana Konovalova ${ }^{12}$, Alexander Sizykh ${ }^{3 *}$ \\ ${ }^{I}$ V.B. Sochava Institute of Geography, Siberian Branch of Russian Academy of Sciences, Irkutsk, 664033, Russia; \\ ${ }^{2}$ Irkutsk State University, 664033 Irkutsk, 126 Ulan-Batorskay str., Russia; \\ ${ }^{3 *}$ Siberian Institute of Plant Physiology and Biochemistry of RAS SB, 664033 Irkutsk, 132 Lermontova str., Russia; \\ "Corresponding Author Alexander Sizykh, e-mail: alexander.sizykh@gmail.com;
}

Received November 2020; Accepted December 2020; Published January 2021;

DOI: https://doi.org/10.31407/ijees11.103

\begin{abstract}
The article presents the peculiarities of the spatial-temporal organization in the geosystems under different physicalgeographic conditions of South-Western and Southern Pre-Baikal. The trends in formation of the plant communities of different landscapes types on the background of changes in the vector of anthropogenic impact are determined for the last 35 years. Basic parameters of the phytocoenoses structure characterizing the facial organization of landscapes are revealed for modern existing environmental conditions in the studied areas.
\end{abstract}

Key words: phytocoenoses, vegetation, geosystems, spatial-temporal organization, Pre-Baikal 